\title{
The assessment of perioperative risk factors of anastomotic leakage after intestinal surgeries; a prospective study
}

\author{
Selmy Awad ${ }^{1 *} \mathbb{D}$, Ahmed Ibrahim Abd El-Rahman ${ }^{1}$, Ashraf Abbas ${ }^{1}$, Waleed Althobaiti ${ }^{2}$, Shaker Alfaran², \\ Saleh Alghamdi², Saleh Alharthi ${ }^{2}$, Khaled Alsubaie², Soliman Ghedan², Rayan Alharthi', Majed Asiri², \\ Azzah Alzahrani ${ }^{2}$, Nawal Alotaibi², Ashraf Shoma ${ }^{1}$ and Mohamed Samir Abou Sheishaa' ${ }^{1}$
}

\begin{abstract}
Background: Anastomotic leaks (AL) are among the most serious complications due to the substantial impact on the quality of life and mortality. Inspite of the advance in diagnostic tools such as laboratory tests and radiological adjuncts, only moderate improvement has been recorded in the rate of detected leaks. The purpose of the research was to assess the perioperative risk factors for $\mathrm{AL}$.

Methods: This study was achieved at MUH and MIH/Egypt within the period between January 2016 and January 2019 for the candidates who underwent bowel anastomosis for small intestinal (except duodenal one) and colorectal pathology. The collected data were analyzed using SPSS of V-26.

Results: This study included 315 cases, among them, 27 cases (8.57\%) developed AL. The percentage of covering stoma was significantly higher in the non-leakage group vs leakage one (24.3\% vs $11.1 \%$ respectively). lower albumin, operative timing, perforation, and covering stoma were shown as significant risk factors for leakage, but with multivariate analysis for these factors, the emergency operation, and serum albumin level was the only independent risk factors that revealed the significance consequently $(p=0.043, p=0.015)$. The analysis of different predictors of $A L$ on the third day showed that the cut-off point in RR was 29 with $83 \%$ sensitivity and $92 \%$ specificity in prediction of leakage, the cut-off point in RR was 118 with 74\% sensitivity and 87\% specificity in prediction of leakage and the cut-off point in CRP was 184.7 with $82 \%$ sensitivity and $88 \%$ specificity in prediction of AL and all had statistically significant value.

Conclusions: The preoperative serum albumin level and the emergency operations are independent risk factors for anastomotic leakage. Moreover, leakage should be highly suspected in cases with rising respiratory rate, heart rate, and CRP levels.
\end{abstract}

Keywords: Anastomosis, Intestinal, Leakage, Predictors

\section{Background}

Anastomotic leakage (AL) after colorectal surgery is more common than that is of the small intestine. Its incidence ranges from 2 to 24\%. This incidence increases

*Correspondence: selmysabry2007@yahoo.com

${ }^{1}$ General Surgery Department, Mansoura University Hospitals,

Mansoura 35516, Egypt

Full list of author information is available at the end of the article with rectal anastomosis more than colonic anastomosis $[1,2]$.

Many risk factors are highly considered with $\mathrm{AL}$ as nature and level of the primary disease, prolonged operative time, absence of proximal diversion increased blood loss and associated systemic disorders like DM, anemia, chronic obstructive pulmonary disease (COPD), malnutrition, hypoalbuminemia, vitamin deficiency, previous irradiation, steroids, male gender, cigarette smoking, 
advanced age, and poor hydration status in the emergency setting as a consequence of sepsis, obstruction, or both [3].

Multiple scoring systems were created for predicting the risk of $\mathrm{AL}$ after intestinal anastomosis. These risk scores include numerous parameters of the previously mentioned risk factors. These scores should help the surgeons to make more safe decisions regarding the performance of anastomosis versus stoma [4].

The risk factors associated with a lower risk of AL are adequate blood supply, assurance of the tension-free anastomosis, adequate matching of the luminal diameters, proper technical placement of sutures, and adequate preoperative antibiotic prophylaxis [5]. AL places a major impact on both physician and patient. Major leaks manifest early and require rapid aggressive management to avoid the development of complications of AL as sepsis and multiorgan failure [6].

Some postoperative signs are associated with $\mathrm{AL}$ as fever, increased leucocytic count, increased CRP level, renal failure, pelvic pain, and peritonitis [7].

Efforts of our two-center were directed to estimate the diagnostic accuracy of the already present parameters and predictors that could be used for prediction and early detection of $\mathrm{AL}$ and to be applied for all patients with intestinal anastomosis.

\section{Methods}

Study design and setting of the study population The research was a prospective observational study. It included the patients at Mansoura University Hospitals (MUH) and Mansoura International Hospital (MIH), Mansoura city, Egypt who underwent small intestinal or colorectal anastomosis for any pathology in the period between January 2016 and January 2019. Out of 315 cases, 27 cases (8.57\%) developed AL after the surgery (leakage group) and the other patients had no leakage (no-leakage group).

Inclusion criteria all Patients who underwent a bowel anastomosis for any cause either at the index operation or second stage reconstruction were recruited. The Patient with Lost follow up or missing data, duodenal injuries, pregnancy, and age $<18$ years were excluded.

Preoperative workup Detailed History taking and thorough Clinical examination was done for all cases with Anesthetic consultation to assess the physical status according to the ASA score system.

The investigations were done for all cases including;

(A) Laboratory:

- Routine preoperative investigations

- Tumor markers: baseline CEA and CA 19-9 for suspected cancer cases.
- $\mathrm{LDH}, \mathrm{CRP}$, and ABG for cases with suspected mesenteric ischemia or perforation.

(B) Radiological:

- Metastatic workup in cases of malignancy.

- Plain X-ray chest, abdominal X-ray, and the abdominal US

- C.T. abdomen and pelvis.

(C) Colonoscopy: Complete colonoscopy up to beyond the caecum was done in almost all elective patients \pm biopsy.

Preoperative preparation All elective patients received standard mechanical (preoperative liquid diet and enemas) and chemical bowel preparation (oral metronidazole and neomycin) apart from patients with the right-sided colonic lesions.

- The cases with low albumin or hemoglobin levels were optimized preoperatively.

- The day before the operation, the cases got the prophylactic antibiotics and VTE chemoprophylaxis in patients with high risks.

The main operative techniques All patients were performed by qualified surgical teams with standard surgical procedures and techniques. In small intestinal lesions, the anastomosis (end-end type) was done in an interrupted fashion in most of our cases. Forty-two cases (including distal colon anastomosis) were done using the stapler technique. The Open approach was the commonly used one. The diversion was performed based on the clinical indications and the patient's general condition.

Post-operative care Most cases were transferred to the ward postoperatively apart from patients demanding intensive ICU monitoring.

- CBC was ordered for all patients daily for the 1st PODs and CRP was withdrawn in the 3rd postoperative day (POD).

- Patients were kept NPO and intravenous fluids and serum electrolytes were optimized.

- The patients, with uneventful postoperative courses, were discharged on the 5th-7th PODs.

- AL was suspected in the presence of abnormal findings of vital signs, clinical examination, and laboratory test. Upon suspicion of AL, the radiologic tools were secured selectively for these patients.

- AL is a defect at the site of the anastomosis with subsequent communication of the intra-luminal compartment with the extraluminal one [8]. It was suggested and determined at the first record of 
an aberrant vital sign, laboratory finding, or upon review of radiologic tools. The postoperative complication is any deviation from the expected normal post-operative course [9].

\section{Data collection and statistical analysis}

Data acquisition was secured after reviewing the medical records of cases and all perioperative variables for each case were collected in the datasheet and were analyzed accordingly. Data analysis and interpretation were done by program SPSS v-26 (IBM, Armonk, NY). Continuous data were presented as mean and standard deviation or as median and range when appropriate, while Categorical data were presented as numbers and percentages. A Pearson's chi-square test and Fisher's exact test were used to compare categorical variables. Student's t-test, the Manne Whitney U test, and one-way ANOVA were used to compare quantitative variables.

The potential relative risks for postoperative variables and Predictors of AL were assessed by univariate (using odds ratio $[\mathrm{OR}]$ ) and multivariate (using risk ratio $[\mathrm{RR}]$ ) analyses with 2-tailed 95\% confidence interval (CI). The risk factors that were significant at a level of $10 \%$ $(\mathrm{p}<0.10)$ in the univariate analysis were used to form initial multivariate model, in which the factors whose level of significance was not below $5 \%(\mathrm{p}<0.05)$ were sequentially excluded.

\section{Results}

Participants and test results; the preoperative demographic data of the cases within the two groups are recorded in Table 1. The gender distribution, median age, $\mathrm{BMI}$ and duration of preoperative preparation did not reveal any significant difference between the two groups. The associated comorbidities were more common in the cases with AL with a statistical significance $(\mathrm{p}=0.039)$. The values of pre-operative routine laboratory investigations and tumor markers are shown in Table 1 with no significant difference apart from serum albumin that was significantly lower in the leakage group vs the no-leakage one (2.9 vs 3.9$)$.

The analysis of the operative data is shown in Table 2. The percentage of cases with an emergency type of operation was significantly higher in the leakage group (66.7\% vs $42.01 \%$ ), as well as that of perforation (14.8\% vs $3.2 \%$ ). The other data did not reveal any significant difference between the two groups.

The results of the postoperative histopathological examination were shown in Table 3 which showed no significant statistical difference in the studied groups. The operative time was longer in the leakage group than the other one. The postoperative data of the cases is shown in Table 3. The percentage of cases with covering stoma was significantly higher in the no-leakage group $(24.3 \%$ vs $11.1 \%)$. The median timing of the start of oral feeding and hospital stay were significantly longer in the leakage group $(\mathrm{p}=0.038, \mathrm{p}=0.009)$. No significant differences were noted between the two groups as regards the postoperative morbidities.

According to clinical manifestations of AL (Table 4), localized peritonitis was detected in 4 cases (14.8\%), diffuse peritonitis was detected in 14 cases $(51.8 \%)$, wound the discharge was detected in 4 cases (14.8\%), and drain discharge was detected in 5 cases (18.5\%).

The US showed a significant diagnostic ability to detect leakage as it was able to detect all cases with leakage in the form of free fluid in 22 cases $(81.5 \%)$ and collection in 5 cases $(18.5 \%)$. However, the US was done at the 5th POD after clinical signs and laboratory markers suggested the presence of leakage. Based on the clinical presentation and general status of the patient, the treatment

Table 1 Preoperative demographic and laboratory data of the study cases

\begin{tabular}{|c|c|c|c|}
\hline Variables & No leakage $(n=288)$ & Leakage $(n=27)$ & P value \\
\hline $\begin{array}{l}\text { Age (years) } \\
\text { Mean (range) }\end{array}$ & $55.5(15-76)$ & $54(18-75)$ & 0.362 \\
\hline Female n (\%) & $173(60.1 \%)$ & $13(48.1 \%)$ & 0.534 \\
\hline $\mathrm{BMI}\left(\mathrm{kg} / \mathrm{m}^{2}\right)$ & $27.66(17.36-62.4)$ & $28(18.2-61.4)$ & 0.164 \\
\hline Smoking n (\%) & $19(6.6 \%)$ & $8(29.6 \%)$ & 0.434 \\
\hline Hypertension n (\%) & $72(25 \%)$ & $10(37 \%)$ & $0.039^{*}$ \\
\hline $\mathrm{DM} n(\%)$ & $58(20.1 \%)$ & $12(44.4 \%)$ & \\
\hline Ischemic heart disease n (\%) & $24(8.3 \%)$ & $5(18.5 \%)$ & \\
\hline Haemoglobin (g/dl) & $11.5(8-16.2)$ & $11.2(7.5-15.6)$ & 0.635 \\
\hline Creatinine (mg/dl) & $0.74(0.4-1.4)$ & $0.69(0.51-1.3)$ & 0.207 \\
\hline Albumin (gm/dl) & $3.9(2.3-4.5)$ & $2.9(2.05-3.8)$ & $0.015^{*}$ \\
\hline CEA $(n g / m l)$ & $2.6(0.2-145)$ & $3.8(0.2-152)$ & 0.096 \\
\hline
\end{tabular}

${ }^{*}$ significant $p$ value $<0.05$ 
Table 2 Perioperative data of the study cases

\begin{tabular}{|c|c|c|c|}
\hline Variables n (\%) & $\begin{array}{l}\text { No leakage } \\
(n=288)\end{array}$ & Leakage $(n=27)$ & $P$ value \\
\hline \multicolumn{4}{|l|}{ Time setting of surgery } \\
\hline Elective & 167 (57.99\%) & $9(33.3 \%)$ & \\
\hline Emergency & $121(42.01 \%)$ & $18(66.7 \%)$ & $0.001^{*}$ \\
\hline Indication of surgery & & & 0.218 \\
\hline Subacute IO & $24(8.3 \%)$ & $3(11.1 \%)$ & \\
\hline Acute abdomen & $73(25.3 \%)$ & $2(7.4 \%)$ & \\
\hline Intraabd. collection & $9(3.2 \%)$ & $4(14.8 \%)$ & \\
\hline CRC & 110 (38.2\%) & $10(37 \%)$ & \\
\hline Ileostomy closure & $24(8.3 \%)$ & $1(3.7 \%)$ & \\
\hline Colostomy closure & $48(16.6 \%)$ & $7(18.5 \%)$ & \\
\hline Causes of perforation & $9(3.2 \%)$ & $4(14.8 \%)$ & $0.019^{*}$ \\
\hline Adenocarcinoma & 3 & 1 & \\
\hline Diverticulosis & 2 & 1 & \\
\hline $\begin{array}{l}\text { Non-sp. inflamma- } \\
\text { tion }\end{array}$ & 3 & 2 & \\
\hline Ischemic enteritis & 1 & 0 & \\
\hline \multicolumn{4}{|l|}{ Type of surgery } \\
\hline $\begin{array}{l}\text { Transverse colec- } \\
\text { tomy }\end{array}$ & $9(3.2 \%)$ & $1(3.7 \%)$ & \\
\hline Lt hemicolectomy & $34(11.9 \%)$ & $4(14.8 \%)$ & 0.136 \\
\hline Ant resection & $53(18.4 \%)$ & $6(2228 \%)$ & \\
\hline Colostomy closure & $48(16.6 \%)$ & $7(18.5 \%)$ & \\
\hline $\begin{array}{l}\text { Small bowel resec- } \\
\text { tion }\end{array}$ & $120(41.7 \%)$ & $10(37.03 \%)$ & \\
\hline \multicolumn{4}{|l|}{ With anastomosis } \\
\hline Ileostomy closure & $24(8.3 \%)$ & $1(3.7 \%)$ & \\
\hline
\end{tabular}

*significant $p$ value $<0.05$

was specifically tailored. Conservative treatment of the leakage was done for 9 cases who had a minor leak without peri-anastomotic contamination and minimal derangement in vital signs while the remaining 18 cases required operations as follows; repair and loop stoma in 4 cases, exteriorization of leaking site in 9 cases, and covering stoma in 5 cases.

Estimates; the lower albumin levels, Time setting of surgery, and perforation were shown in Table 5 as significant risk factors for the presence of leakage, but after using multivariate analysis for the three parameters, the emergency operation and albumin level was the only independent risk factors that revealed the significance $\left(\mathrm{p}=0.017^{*}, \mathrm{p}=0.042^{*}\right)$. Other parameters in the study failed to achieve a statistically significant predictive value.

Comparison of the different postoperative laboratory and clinical parameters between the two groups is shown in Table 6. The mean HR revealed a significant difference on the 3rd and the 4th PODs $(p=0.038, p=0.011)$. In the same way, the mean $R R$ revealed a significant difference on the 3rd and the 4th PODs $(\mathrm{p}=0.025, \mathrm{p}<0.001)$. The mean serum levels of CRP showed a statistically significant difference between the two groups beginning from the $1^{\text {st }}$ POD being higher in the cases with AL $(\mathrm{p}<0.001)$. The analysis of different predictors of AL on the 3rd POD showed that the cut-off point in RR was 29 with $83 \%$ sensitivity and $92 \%$ specificity in prediction of AL, the cutoff point in RR was 118 with $74 \%$ sensitivity and $87 \%$ specificity in prediction of AL and the cut-off point in CRP was 184.7 with $82 \%$ sensitivity and $88 \%$ specificity in the prediction of AL and all with statistically significant value. These data are shown in Table 6 and Figs. 1, 2, 3.

\section{Discussion}

Despite the continual improvement in surgical techniques, $\mathrm{AL}$ remains one of the most devastating consequences that can occur from bowel surgery. It is associated with rising reoperation rates, length of hospital stay, morbidity, and mortality. The incidence of AL after colorectal resections is between 1 and $12 \%$ overall and up to 10 to $14 \%$ in low colorectal ones [10-12].

The rates of morbidity and mortality significantly increase after $\mathrm{AL}$, with mortality reported between 12 and $27 \%$. Although AL has increasingly been an outcome of interest, it remains difficult to predict the risk of an individual patient. The prediction of AL can introduce a vital role in determining postoperative outcomes and can facilitate decision making in elderly patients undergoing intestinal surgeries [13-15].

The objective of this research was to detect the risk factors for AL as well as its early predictors after bowel resection. So, this study included 315 cases who underwent surgery for small intestinal or colorectal disease from January 2016 till January 2019. Among these cases, 27 cases $(8.57 \%)$ developed AL after the surgery. Similar results were reported by a previous study [16].

In this study, the median age, gender distribution, BMI, and duration of preoperative preparation did not reveal any significant difference. The median age of the cases in the leakage group was 54 years with a range between 18 and 75 years. There were 14 males ( $51.8 \%$ of cases) and 13 females (48.1\% of the cases) in the cases with leakage. Similar results were reported by Kream and his colleagues [17].

In our study, age was not a significant predictor for AL. This is in contrast to another study included a series of 1391 cases undergoing rectal operations reported that age above 60 years is still an independent parameter for AL [18].

The associated comorbidities were significantly more common in the group of $\mathrm{AL}(\mathrm{p}=0.039)$. DM was the most common associated comorbidity and was detected in $37 \%$ and $20.1 \%$ in the cases with leakage and nonleakage group respectively, followed by HTN that was 
Table 3 Perioperative variables of the outcome of the study groups

\begin{tabular}{|c|c|c|c|}
\hline Variables n (\%) & No leakage $(n=288)$ & Leakage $(n=27)$ & P value \\
\hline Covering stoma & $70(\%$ 24.3) & $3(11.1 \%)$ & $0.005^{*}$ \\
\hline \multicolumn{4}{|l|}{ The technique } \\
\hline Stapler & $38(13.3 \%)$ & $4(14.8 \%)$ & \\
\hline Hand sewn & $250(86.7 \%)$ & $23(85.2 \%)$ & 0.518 \\
\hline $\begin{array}{l}\text { Operative time (h) } \\
\text { Mean (range) }\end{array}$ & $3(1-5)$ & $4(2-6)$ & 0.065 \\
\hline Blood transfusion & $36(12.5 \%)$ & $3(11.1 \%)$ & 0.164 \\
\hline \multicolumn{4}{|l|}{ Pathology } \\
\hline Adenocarcinoma & $110(38.2 \%)$ & $10(37 \%)$ & \\
\hline Diverticulosis & $6(2.1 \%)$ & $1(3.7 \%)$ & 0.248 \\
\hline Non-specific inflammation & $115(39.9 \%)$ & $11(40.7 \%)$ & \\
\hline MVO & $36(12.5 \%)$ & $3(11.1 \%)$ & \\
\hline Ischemic enteritis & $21(7.3 \%)$ & $2(7.4 \%)$ & \\
\hline $\begin{array}{l}\text { Oral feeding (day) } \\
\text { Mean (range) }\end{array}$ & $4(0-8)$ & $5(1-10)$ & $0.038^{*}$ \\
\hline \multicolumn{4}{|l|}{ Morbidity } \\
\hline Wound & $35(12.2 \%)$ & $3(11.1 \%)$ & \\
\hline infection lleus & $148(51.4 \%)$ & $13(48.1 \%)$ & 0.154 \\
\hline Wound dehiscence & $4(1.4 \%)$ & $3(11.1 \%)$ & \\
\hline $\begin{array}{l}\text { Hospital stay (day) } \\
\text { Mean (range) }\end{array}$ & $6(5-12)$ & $10(7-24)$ & $0.009^{*}$ \\
\hline
\end{tabular}

*significant $p$ value $<0.05$

\section{Table 4 The data set of management of anastomotic leakage cases}

\begin{tabular}{lc}
\hline Variables $\mathbf{n}$ (\%) & $\begin{array}{l}\text { Leakage } \\
\text { group } \\
\text { (n=27) }\end{array}$ \\
\hline The main presentation of leakage & \\
Localized peritonitis & $4(14.8 \%)$ \\
Diffuse peritonitis & $14(51.8 \%)$ \\
Wound discharge & $4(14.8 \%)$ \\
Drain discharge & $5(18.5 \%)$ \\
Radiology & \\
Ultrasonography findings & \\
Intra-peritoneal free fluid & \\
Intra-peritoneal collections & $22(81.5 \%)$ \\
Computerized tomography findings & $5(18.5 \%)$ \\
Free passage of the dye & \\
Peri-anastomotic free fluid or collections & $3(11.11 \%)$ \\
Peri-anastomotic gas bubbles & $4(14.8 \%)$ \\
Intra-peritoneal free fluid & $3(11.11 \%)$ \\
Intra-peritoneal collections & $10(37.03 \%)$ \\
Management of leakage & $7(25.92 \%)$ \\
Conservative & \\
Operative; & $9(33.3 \%)$ \\
Repair and loop stoma & $18(66.7 \%)$ \\
Exteriorization of leaking site & $4(14.8 \%)$ \\
Covering stoma only & $9(33.3 \%)$ \\
& $5(18.5 \%)$ \\
\hline
\end{tabular}

Table 5 analysis of the preoperative risk factors (predictors) of AL

\begin{tabular}{|c|c|c|c|c|}
\hline \multirow[t]{2}{*}{ Variables } & \multicolumn{2}{|c|}{ Univariate analysis } & \multicolumn{2}{|c|}{ Multivariate analysis } \\
\hline & OR $(95 \% \mathrm{Cl})$ & $P$ value & RR $(95 \%$ Cl) & $P$ value \\
\hline Albumin & $0.46(0.35-1.23)$ & $0.015^{*}$ & $2.37(1.823-3.94)$ & $0.042^{*}$ \\
\hline $\begin{array}{l}\text { Time setting } \\
\text { of surgery } \\
\text { (elective/ } \\
\text { emergency) }\end{array}$ & $0.47(0.25-0.98)$ & $0.001 *$ & $2.26(2.93-3.72)$ & $0.017^{*}$ \\
\hline $\begin{array}{l}\text { Covering } \\
\text { stoma in } \\
\text { colonic cases }\end{array}$ & $0.05(0.02-0.46)$ & $0.003^{*}$ & $1.31(0.76-2.302)$ & 0.129 \\
\hline
\end{tabular}

detected in $37 \%$ and $25 \%$, respectively. Two pieces of research observed DM as an independent risk factor for $\operatorname{AL}[19,20]$. Other results of literature, do not find diabetes to be a significant factor for AL [21]. In our study, smoking was not a significant predictor for AL. this is in contrast with several studies that have found that current smoking status is an independent predictor [22, 23].

In our study, increased BMI was not a significant predictor for AL. This is in contrast with several types of research [24, 25]. In our study, the duration of bowel preparation was not associated with a decrease in the risk of AL. This is in agreement with several trials that have 
Table 6 Analysis of the postoperative risk factors (early detection) of AL

\begin{tabular}{|c|c|c|c|c|c|c|}
\hline \multicolumn{2}{|l|}{ mean $\pm S D$} & \multicolumn{2}{|c|}{ Non_leakage group } & \multicolumn{2}{|c|}{ Leakage group } & $P$ value \\
\hline \multicolumn{7}{|l|}{$H R(B / \min )$} \\
\hline \multicolumn{2}{|l|}{ 1st POD } & \multicolumn{2}{|c|}{$96.04 \pm 15.74$} & \multicolumn{2}{|c|}{$95.73 \pm 13.56$} & $p=0.274$ \\
\hline \multicolumn{2}{|l|}{ 2nd POD } & \multicolumn{2}{|c|}{$95.52 \pm 10.38$} & \multicolumn{2}{|c|}{$97.42 \pm 15.63$} & $p=0.141$ \\
\hline \multicolumn{2}{|l|}{ 3rd POD } & \multicolumn{2}{|c|}{$93.71 \pm 11.17$} & \multicolumn{2}{|c|}{$103.63 \pm 7.94$} & $p=0.038^{*}$ \\
\hline \multicolumn{2}{|l|}{ 4th POD } & \multicolumn{2}{|l|}{$90.26 \pm 6.86$} & \multicolumn{2}{|c|}{$105.91 \pm 8.12$} & $p=0.011^{*}$ \\
\hline \multicolumn{7}{|c|}{ RR (cycle/min) } \\
\hline \multicolumn{2}{|l|}{ 1st POD } & \multicolumn{2}{|l|}{$20.73 \pm 1.86$} & \multicolumn{2}{|l|}{$21.37 \pm 1.56$} & $p=0.483$ \\
\hline \multicolumn{2}{|l|}{ 2nd POD } & \multicolumn{2}{|l|}{$19.62 \pm 0.38$} & \multicolumn{2}{|l|}{$21.87 \pm 1.63$} & $p=0.137$ \\
\hline \multicolumn{2}{|l|}{ 3rd POD } & \multicolumn{2}{|l|}{$19.02 \pm 0.25$} & \multicolumn{2}{|l|}{$23.64 \pm 1.85$} & $p=0.025^{*}$ \\
\hline 4th POD & & \multicolumn{2}{|l|}{$18.38 \pm 0.47$} & \multicolumn{2}{|l|}{$26.38 \pm 0.95$} & $\mathrm{p}<0.001^{* *}$ \\
\hline \multicolumn{7}{|l|}{$\operatorname{CRP}(\mathrm{mg} / \mathrm{L})$} \\
\hline 1st POD & & \multicolumn{2}{|l|}{$35.63 \pm 9.86$} & \multicolumn{2}{|c|}{$85.97 \pm 21.56$} & $p<0.001^{* *}$ \\
\hline 2nd POD & & \multicolumn{2}{|c|}{$81.97 \pm 19.38$} & \multicolumn{2}{|c|}{$120.46 \pm 31.02$} & $p<0.001^{* *}$ \\
\hline 3rd POD & & \multicolumn{2}{|c|}{$107.02 \pm 27.25$} & \multicolumn{2}{|c|}{$200.73 \pm 44.2$} & $\mathrm{p}<0.001^{* *}$ \\
\hline \multirow[t]{2}{*}{ 4th POD } & & $104.36 \pm 28$ & & $205.27 \pm 49$ & & $p<0.001^{* *}$ \\
\hline & AUC & Cut off point & $P$ value & Sensitivity (\%) & Specificity (\%) & $\begin{array}{l}\text { Accuracy } \\
\text { (\%) }\end{array}$ \\
\hline $\mathrm{RR}$ & 0.921 & 29 & $0.001^{*}$ & 83 & 92 & 89 \\
\hline$H R$ & 0.895 & 118 & $0.002^{*}$ & 74 & 87 & 85 \\
\hline CRP & 0.872 & 184.7 & $0.009^{*}$ & 82 & 88 & 85 \\
\hline
\end{tabular}

*significant $\mathrm{p}$ value $<0.05$; **highly significant $\mathrm{p}$ value $<0.001$

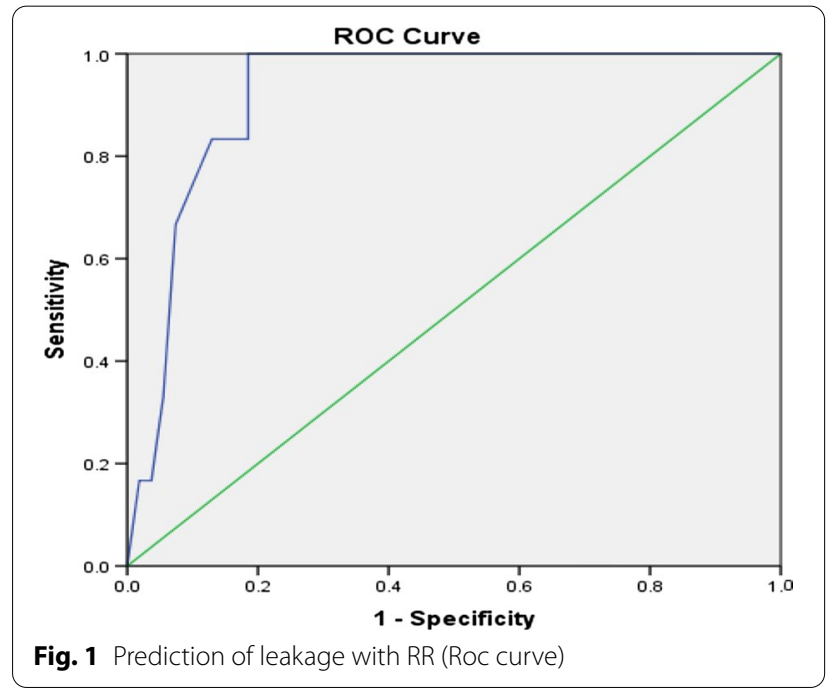

reported omitting bowel preparation does not increase the risk of AL [26, 27].

In a recent study, patient-related factors (male sex, higher ASA score, COPD, previously infected wound, steroid use, diabetes mellitus, and recent weight loss) and surgery-related factors (open technique or prolonged operation) were found to be independent predictors of $\mathrm{AL}$ [15] which were in accordance with the literature [17].

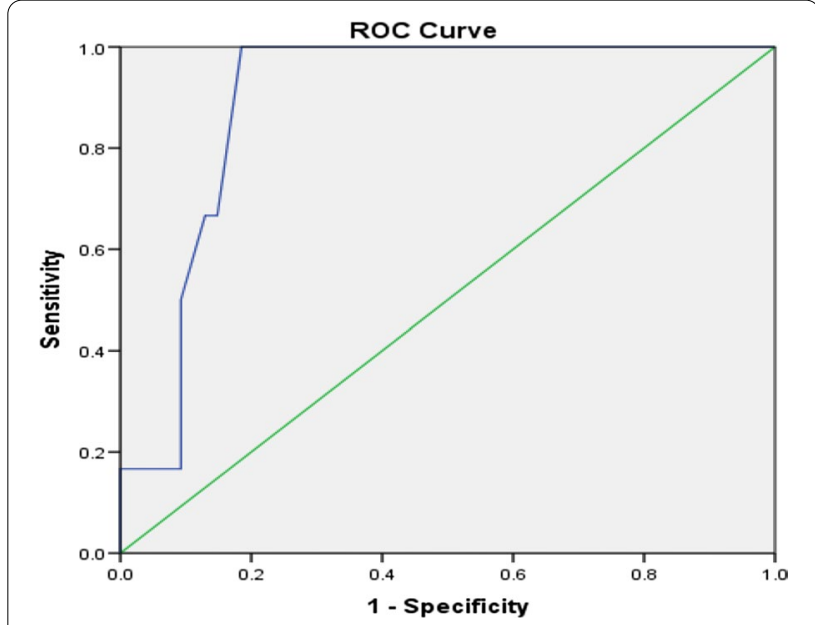

Fig. 2 Prediction of leakage with HR (Roc curve)

In the current study, The lower albumin levels, the emergent time setting of surgery and the perforation presence was shown (Table 5) as significant risk factors for the presence of leakage, but after using multivariate analysis for the three parameters, the emergency operation, and albumin level were the only independent risk factors that revealed significance $\left(\mathrm{p}=0.017^{*}, \mathrm{RR} 2.26\right.$ (2.93-3.72); $\mathrm{p}=0.042^{*}$, $\left.\mathrm{RR} 2.37(1.823-3.94)\right)$. This is in accordance with another study where the emergent 


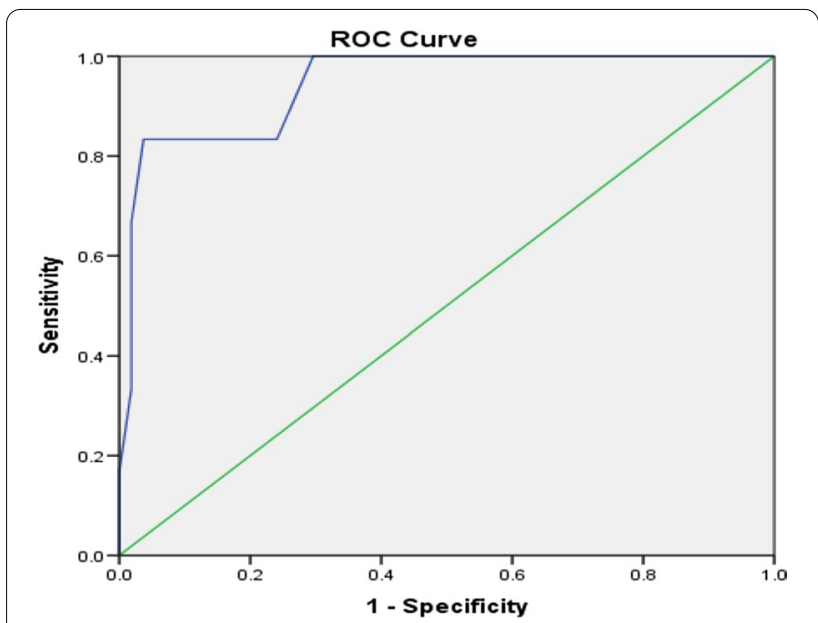

Fig. 3 Prediction of leakage with CRP (Roc curve)

setting of surgery is an independent predictor for $\mathrm{AL}$ (RR 4.6, 95\% C.I. 1.9 to 9.8) [3]. Other parameters in the study failed to achieve a statistically significant predictive value.

In the present study, the type of anastomotic technique was not a predictor for the occurrence of AL. A significantly increased rate of radiological leaks in the sutured group was reported by a randomized control trial (RCT) comparing stapled with sutured anastomosis [28].

In our study, the type of covering stoma was a dependent predictor for AL, but with multi regression model analysis, it was not an independent predictor for AL. The same observation was reported with a recent RCT as the leak rate was $5.5 \%$ in the defunctioned group compared with $37.5 \%$ in the one with no stoma [29].

In this study, the nature of the disease whether benign or malignant did not affect the occurrence of AL. This was in accordance with Park et al. [30]where the nature and the stage of the disease did not affect the incidence of AL.

In our study, the operative time and the intraoperative blood loss were not shown to be predictors for the occurrence of AL. Our results came in agreement with the literature that reported an increased length of hospital stay ( 13 vs $5 \mathrm{~d} ; p<0.001)$, higher readmission $(43.5 \%$ vs $8.3 \% ; p<0.001)$, and reoperation rates $(p<0.001)$ in patients with colectomy who had AL compared with those who did not [31].

In this study, According to postoperative pathology, types of pathological disease failed to achieve any significant difference between the leakage and the non-leakage group even MVO. Our protocol was to take a wide safety margin to avoid impending ischemic segments as the normal healing process of the anastomosis to take place, it must have ample tissue perfusion [32].
The current study evaluated the effect of AL on postoperative outcomes. The same results were noted in Patients in whom AL developed had a longer hospital stay, more postoperative complications, a longer time for the return of bowel functions, and higher readmission rates [15].

According to the main presentation of $\mathrm{AL}$, localized peritonitis was detected in 4 cases (14.8\%), diffuse peritonitis was detected in 14 cases $(51.8 \%)$, wound discharge was detected in 4 cases (14.8\%) and drain discharge was detected in 5 cases (18.5\%). This was in agreement with the results from the literature reported that general peritonitis is one of the most severe outcome for AL [33].

Different clinical presentations can be manifested with AL ranging from abdominal discomfort, and fever, up to severe sepsis. Altered sensorium with pulmonary abnormalities is commonly presented early in AL [34].

In this study, US and CT showed a significant diagnostic ability to detect leakage as both of them were able to detect all cases with leakage in the form of free fluid and collection. Radiologic findings were frequently demanding proper correlation with the clinical presentation. When the radiologic studies appear to be negative, a high index of suspicion should be maintained. As on the one hand, one study found that the sensitivity for contrastenhanced CT scan is in the range of $50 \%$ in the setting of a leak [35]. The overlapping of radiologic findings is commonly encountered in patients with or without a leak. Only loculated fluid with air was reported more frequently in patients with AL [36].

In our study, the mean postoperative HR showed a significant difference between the two groups on the 3rd and 4th PODs $(\mathrm{p}=0.038, \mathrm{p}=0.011)$. In the same way, the mean RR revealed a significant difference between the two groups on the 3rd and 4th PODs $(p=0.025$, $\mathrm{p}<0.001$ ). On the contrary, the number of WBCs and body temperature did not show a significant difference in the period of postoperative follow-up for 4 days. Our findings were consistent with previous research which found that fever and leukocytosis were not commonly present, and when present manifested in the late PODs [34].

In our study, Conservative treatment of the leakage was done for 9 cases while the remaining 18 cases required operations as follows; repair and loop stoma in 4 cases, exteriorization of leaking site in 9 cases, and covering the stoma in 5 cases. This was in agreement with Nikolian et al. [37] who found that most of the cases diagnosed with major $\mathrm{AL}$ underwent re-operative interventions. Also, the reoperation rate for AL in our study is consistent with previously published research [38].

Also, in this study, the mean serum levels of CRP revealed a statistically significant difference between the 
cases with leakage and no-leakage beginning from the 1st POD being higher in the cases with AL $(\mathrm{p}<0.001)$. Also, in our study, all postoperative $\mathrm{HR}, \mathrm{RR}$, and CRP were significant predictors for the occurrence of AL with a sensitivity of $83 \%, 74 \%$, and $82 \%$ respectively.

The modified DULK score of AL included; RR '20 breaths/min, clinical deterioration, abdominal pain (other than wound pain), and CRP level ' $250 \mathrm{mg} / \mathrm{l}$. However, CRP is not sensitive to the detection of AL because it may be increased with any other infection [7].

In our study, the analysis of different predictors of $\mathrm{AL}$ on the 3rd day showed that the cut-off point in RR was 29 with $83 \%$ sensitivity and $92 \%$ specificity in prediction of leakage, the cut-off point in RR was 118 with $74 \%$ sensitivity and $87 \%$ specificity in prediction of leakage and the cut-off point in CRP was 184.7 with $82 \%$ sensitivity and $88 \%$ specificity in prediction of leakage and all have statistically significant values.

The current study had some limitations, as it was only a two-center study, and the sample size may be considered relatively small, which restricts the power of conclusions. Also, the study included a heterogeneous group of patients of small intestinal and colorectal surgery, since anastomoses in these locations lead to different numbers of leakage rates with different pathology. Moreover, they have different pathophysiological pathways underlying AL with different aetiological factors. Therefore, wide further improvements are needed in other future studies. Large numbers of homogenous series are suggested to confirm these results and proceed for establishing a new score for prediction and early detection of AL.

\section{Conclusion}

The preoperative serum albumin level and emergency operations are independent risk factors for anastomotic leakage. Moreover, leakage should be suspected and predicted in cases with a high respiratory rate, heart rate, and CRP levels.

\begin{abstract}
Abbreviations
AL: Anastomotic leaks; POD: Postoperative day; ASA: American Society of Anesthesia; BMI: Body mass index; COPD: Chronic obstructive pulmonary disease; MIH: Mansoura University Hospitals; MIH: Mansoura International Hospital; RCT: Randomized control trial; DM: Diabetes mellitus; CRP: C-reactive protein; LDH: Lactic dehydrogenase; ABG: Arterial blood gases; RR: Respiratory rate; HR: Heart rate; IO: Intestinal obstruction; CRC: Colorectal carcinoma; MVO: Mesenteric vascular occlusion; OR: Odds ratio; RR: Risk ratio; Cl: Confidence interval; ROC: Receiver operating characteristic; AUC: Area under curve.
\end{abstract}

\section{Acknowledgements}

No further competing interests to declare.

\section{Authors' contributions}

SA, AIA, AAA, WA, ShA: Study design, data collection and analysis, manuscript writing, and manuscript revision. SG A, SA A, K A: Study design, data collection and analysis, and manuscript writing. So G, A,M A: Study design, data collection and manuscript writing. A A, NA: Data collection and manuscript revision.
AS, M SA: Data analysis and manuscript revision. All authors have read and approved the final manuscript.

Funding

Not applicable.

Availability of data and materials

The datasets used and/or analysed during the current study are available from the corresponding author on reasonable request.

\section{Ethics approval and consent to participate}

Ethical approval was secured from the local IRB before the start of the study. Written Patient consent had been taken for participation in the study.

\section{Consent for publication}

Not applicable as no individual data included.

\section{Competing interests}

Not applicable.

\section{Author details}

${ }^{1}$ General Surgery Department, Mansoura University Hospitals, Mansoura 35516, Egypt. ${ }^{2}$ General Surgery Department, King Faisal Medical Complex, Taif, Saudi Arabia.

Received: 15 September 2020 Accepted: 28 December 2020 Published online: 07 January 2021

\section{References}

1. Komen N, Morsink M, Beiboer S, Miggelbrink A, Willemsen P, van der Harst

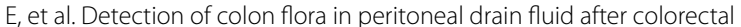
surgery: can RT-PCR play a role in diagnosing anastomotic leakage? J Microbiol Methods. 2009;79(1):67-70.

2. Frasson M, Flor-Lorente B, Rodríguez JLR, Granero-Castro P, Hervás D, Alvarez Rico MA, et al. Risk factors for anastomotic leak after colon resection for cancer. Ann Surg. 2015;262(2):321-30.

3. Choi G-S, Park IJ, Kang BM, Lim KH, Jun S-H. A novel approach of roboticassisted anterior resection with transanal or transvaginal retrieval of the specimen for colorectal cancer. Surg Endosc. 2009;23(12):2831.

4. Dekker JWT, Liefers GJ, van Otterloo JCdM, Putter H, Tollenaar RA. Predicting the risk of anastomotic leakage in left-sided colorectal surgery using a colon leakage score. J Surg Res. 2011;166(1):e27-34.

5. Sciuto A, Merola G, De Palma GD, Sodo M, Pirozzi F, Bracale UM, et al. Predictive factors for anastomotic leakage after laparoscopic colorectal surgery. World J Gastroenterol. 2018;24(21):2247.

6. Varon J, Marik PE. Perioperative hypertension management. Vasc Health Risk Manag. 2008;4(3):615-27. https://doi.org/10.2147/vhrm.s2471.

7. Den Dulk M, Witvliet M, Kortram K, Neijenhuis P, de Hingh I, Engel A, et al. The DULK (Dutch leakage) and modified DULK score compared: actively seek the leak. Colorectal Dis. 2013;15(9):e528-33.

8. Rahbari NN, Weitz J, Hohenberger W, Heald RJ, Moran B, Ulrich A, et al. Definition and grading of anastomotic leakage following anterior resection of the rectum: a proposal by the International Study Group of Rectal Cancer. Surgery. 2010;147(3):339-51.

9. Clavien PA, Barkun J, De Oliveira ML, Vauthey JN, Dindo D, Schulick RD, et al. The Clavien-Dindo classification of surgical complications: five-year experience. Ann Surg. 2009;250(2):187-96.

10. Shogan BD, Carlisle EM, Alverdy JC, Umanskiy K. Do we really know why colorectal anastomoses leak? J Gastrointest Surg. 2013;17(9):1698-707.

11. Nasir Khan MU, Abir F, Longo W, Kozol R. Anastomotic disruption after large bowel resection. World J Gastroenterol WJG. 2006;12(16):2497.

12. Trencheva K, Morrissey KP, Wells M, Mancuso CA, Lee SW, Sonoda T, et al. Identifying important predictors for anastomotic leak after colon and rectal resection: prospective study on 616 patients. Ann Surg. 2013;257(1):108-13.

13. Thornton $M$, Joshi $H$, Vimalachandran $C$, Heath $R$, Carter $P$, Gur U, et al. Management and outcome of colorectal anastomotic leaks. Int J Colorectal Dis. 2011;26(3):313-20. 
14. Law WL, Choi HK, Lee YM, Ho JW, Seto CL. Anastomotic leakage is associated with poor long-term outcome in patients after curative colorectal resection for malignancy. J Gastrointest Surg. 2007;11(1):8-15.

15. Rencuzogullari A, Benlice C, Valente M, Abbas MA, Remzi FH, Gorgun E. Predictors of anastomotic leak in elderly patients after colectomy: nomogram-based assessment From the American College of Surgeons National Surgical Quality Program Procedure-Targeted Cohort. Dis Colon Rectum. 2017;60(5):527-36.

16. Segelman J, Mattsson I, Jung B, Nilsson P, Palmer G, Buchli C. Risk factors for anastomotic leakage following ileosigmoid or ileorectal anastomosis. Colorectal Dis. 2018;20(4):304-11.

17. Kream J, Ludwig KA, Ridolfi TJ, Peterson CY. Achieving low anastomotic leak rates utilizing clinical perfusion assessment. Surgery. 2016;160(4):960-7.

18. Jung SH, Yu CS, Choi PW, Kim DD, Park IJ, Kim HC, et al. Risk factors and oncologic impact of anastomotic leakage after rectal cancer surgery. Dis Colon Rectum. 2008;51(6):902

19. Manson PN, Corman ML, Coller JA, Veidenheimer MC. Anastomotic recurrence after anterior resection for carcinoma: Lahey Clinic experience. Dis Colon Rectum. 1976;19(3):219-24

20. Vignali A, Fazio VW, Lavery IC, Milsom JW, Church JM, Hull TL, et al. Factors associated with the occurrence of leaks in stapled rectal anastomoses: a review of 1,014 patients. J Am Coll Surg. 1997;185(2):105-13.

21. Ziegler MA, Catto JA, Riggs TW, Gates ER, Grodsky MB, Wasvary HJ. Risk factors for anastomotic leak and mortality in diabetic patients undergoing colectomy: analysis from a statewide surgical quality collaborative. Arch Surg. 2012;147(7):600-5.

22. Kruschewski M, Rieger H, Pohlen U, Hotz HG, Buhr HJ. Risk factors for clinical anastomotic leakage and postoperative mortality in elective surgery for rectal cancer. Int J Colorectal Dis. 2007;22(8):919-27.

23. Richards C, Campbell V, Ho C, Hayes J, Elliott T, Thompson-Fawcett M. Smoking is a major risk factor for anastomotic leak in patients undergoing low anterior resection. Colorectal Dis. 2012;14(5):628-33.

24. Benoist S, Panis Y, Alves A, Valleur P. Impact of obesity on surgical outcomes after colorectal resection. Am J Surg. 2000;179(4):275-81.

25. Senagore AJ, Delaney CP, Madboulay K, Brady KM, Fazio CVW. Laparoscopic colectomy in obese and nonobese patients. J Gastrointest Surg. 2003:7(4):558-61.

26. Slim K, Vicaut E, Launay-Savary MV, Contant C, Chipponi J. Updated systematic review and meta-analysis of randomized clinical trials on the role of mechanical bowel preparation before colorectal surgery. Ann Surg. 2009:249(2):203-9.
27. van't Sant HP, Weidema WF, Hop WC, Oostvogel HJ, Contant CM. The influence of mechanical bowel preparation in elective lower colorectal surgery. Ann Surg. 2010;251(1):59-63.

28. Chude G, Rayate N, Patris V, Koshariya M, Jagad R, Kawamoto J, et al. Defunctioning loop ileostomy with low anterior resection for distal rectal cancer: should we make an ileostomy as a routine procedure? A prospective randomized study. Hepatogastroenterology. 2008;55(86-87):1562-7.

29. Ulrich $A B$, Seiler C, Rahbari N, Weitz J, Büchler MW. Diverting stoma after low anterior resection: more arguments in favor. Dis Colon Rectum. 2009;52(3):412-8

30. Park JS, Huh JW, Park YA, Cho YB, Yun SH, Kim HC, et al. Risk factors of anastomotic leakage and long-term survival after colorectal surgery. Medicine. 2016. https://doi.org/10.1097/MD.0000000000002890.

31. Midura EF, Hanseman D, Davis BR, Atkinson SJ, Abbott DE, Shah SA, et al. Risk factors and consequences of anastomotic leak after colectomy: a national analysis. Dis Colon Rectum. 2015;58(3):333-8.

32. Thompson SK, Chang EY, Jobe BA. Clinical review: healing in gastrointestinal anastomoses, part I. Microsurgery. 2006;26(3):131-6.

33. Lim S-B, Yu CS, Kim CW, Yoon YS, Park IJ, Kim JC. The types of anastomotic leakage that develop following anterior resection for rectal cancer demonstrate distinct characteristics and oncologic outcomes. Int J Colorectal Dis. 2015;30(11):1533-40.

34. Bellows C, Webber L, Albo D, Awad S, Berger D. Early predictors of anastomotic leaks after colectomy. Tech Coloproctol. 2009;13(1):41-7.

35. Nesbakken A, Nygaard K, Lunde O, Blücher J, Gjertsen O, Dullerud R. Anastomotic leak following mesorectal excision for rectal cancer: true incidence and diagnostic challenges. Colorectal Dis. 2005;7(6):576-81.

36. Power N, Atri M, Ryan S, Haddad R, Smith A. CT assessment of anastomotic bowel leak. Clin Radiol. 2007;62(1):37-42.

37. Nikolian VC, Kamdar NS, Regenbogen SE, et al. Anastomotic leak after colorectal resection: a population-based study of risk factors and hospital variation. Surgery. 2017;161(6):1619-27. https://doi.org/10.1016/j. surg.2016.12.033

38. Hyman NH, Osler T, Cataldo P, Burns EH, Shackford SR. Anastomotic leaks after bowel resection: what does peer review teach us about the relationship to postoperative mortality? J Am Coll Surg. 2009;208(1):48-52.

\section{Publisher's Note}

Springer Nature remains neutral with regard to jurisdictional claims in published maps and institutional affiliations.
Ready to submit your research? Choose BMC and benefit from:

- fast, convenient online submission

- thorough peer review by experienced researchers in your field

- rapid publication on acceptance

- support for research data, including large and complex data types

- gold Open Access which fosters wider collaboration and increased citations

- maximum visibility for your research: over 100M website views per year

At BMC, research is always in progress.

Learn more biomedcentral.com/submissions 